Revue

Revue de l'histoire des religions

del'histoire

des religions

$1 \mid 2017$

Varia

Robert DANIELUK et Bernard JOASSART (éd.), Au service de la réconciliation des Églises. Jean Gagarin, Jean Martynov et Victor De Buck. Correspondance

Bruxelles, Société des Bollandistes («Tabularium hagiographicum », 7), 2014

Laura Pettinaroli

\title{
OpenEdition
}

Journals

Édition électronique

URL : http://journals.openedition.org/rhr/8717

DOI : 10.4000/rhr.8717

ISSN : 2105-2573

Éditeur

Armand Colin

Édition imprimée

Date de publication : 1 mars 2017

Pagination : 196-199

ISBN : 978-2-200-93125-4

ISSN : 0035-1423

Référence électronique

Laura Pettinaroli, «Robert Danieluk et Bernard Joassart (éd.), Au service de la réconciliation des Églises. Jean Gagarin, Jean Martynov et Victor De Buck. Correspondance », Revue de I'histoire des religions [En ligne], 1 | 2017, mis en ligne le 24 mars 2017, consulté le 08 janvier 2021. URL : http:// journals.openedition.org/rhr/8717 ; DOI : https://doi.org/ERREUR PDO dans /localdata/www-bin/ Core/Core/Db/Db.class.php L.34 : SQLSTATE[HY000] [2006] MySQL server has gone away

Ce document a été généré automatiquement le 8 janvier 2021

Tous droits réservés 


\section{Robert DANIELUK et Bernard JOASSART (éd.), Au service de la réconciliation des Églises. Jean Gagarin, Jean Martynov et Victor De Buck. Correspondance}

Bruxelles, Société des Bollandistes («Tabularium hagiographicum », 7), 2014

Laura Pettinaroli

\section{RÉFÉRENCE}

Robert DANIELUK et Bernard JOASSART (éd.), Au service de la réconciliation des Églises. Jean Gagarin, Jean Martynov et Victor De Buck. Correspondance, Bruxelles, Société des Bollandistes ("Tabularium hagiographicum », 7), 2014, 24,5 cm, 1284- [35] p. [p. 81 à 1284 sur CD-ROM], $45 €$, ISBN 978-2-87365-029-2.

1 L'archiviste Robert Danieluk et le bollandiste Bernard Joassart ont associé leurs compétences pour proposer une très belle publication de sources. En effet, en éditant la correspondance échangée entre le bollandiste Victor De Buck et les jésuites Ivan Gagarin et Jean Martynov entre 1853 et 1876, les deux auteurs ont croisé leurs centres d'intérêt, R. Danieluk ayant consacré des travaux au groupe des jésuites russes, alors que B. Joassart a publié plusieurs volumes soulignant l'insertion des bollandistes dans les milieux érudits depuis le xvII siècle.

La grande qualité formelle de l'édition mérite d'être d'emblée saluée: outre l'introduction, qui présente les protagonistes et les thématiques abordées (p. 9-42), les annotations au fil du texte éclairent précisément les références aux événements et aux personnages. Pour s'orienter dans cet ensemble massif (plus de 1200 pages de documents), les auteurs proposent une chronologie (p. 49-52), une liste des documents édités (p. 65-78), ainsi qu'un index onomastique (p. [3]- [33]). Les pages 81 à 1284 de 
l'ouvrage sont disponibles uniquement sur CD-ROM (fichier pdf) : la version papier ne comprend donc que l'introduction, les tables et l'index (muni d'une pagination spécifique). La publication électronique des documents constitue plutôt un bienfait pour le lecteur, dont la «navigation » dans le texte est facilitée par des recherches par mots-clés.

3532 lettres sont publiées, dont 355 échangées entre De Buck et Gagarin de 1853 à 1876 et 177 par De Buck et Martynov entre 1858 et 1876 (530 documents sont numérotés car s'y ajoutent les doc. 116bis et 351bis). Ces lettres proviennent des archives jésuites françaises (Vanves) et des archives bollandistes (Bruxelles). Toutes les lettres sont en français même si ce n'était la langue maternelle d'aucun des trois correspondants. En effet, Gagarin (1814-1882) et Martynov (1821-1894), nés en Russie, se convertissent au catholicisme et rejoignent la Compagnie de Jésus en France dans les années 1840, alors que Victor De Buck (1817-1876), originaire de Flandre, entre dans la Compagnie en 1835 puis chez les bollandistes à Bruxelles en 1840. Il s'agit toutefois d'une langue parsemée d'expressions latines, italiennes, anglaises, alors que les correspondants se déplacent de Bruxelles à Rome, mais aussi de Paris à Ghazir, Jérusalem ou Vienne, mettant ainsi en lumière l'importance des échanges internationaux dans cette culture religieuse au cœur du xix ${ }^{e}$ siècle.

4 La richesse de ces lettres (dont De Buck avait conscience lorsqu'il affirmait en 1858 que la «collection" des lettres de Gagarin "pourra être un jour utile pour l'histoire de l'“agitation" russe ", doc. 88) méritait bien une publication, même si la correspondance Martynov-De Buck, moins abondante, plus hachée et érudite, intéressera sans doute un public plus restreint que les échanges Gagarin-De Buck, qui abordent des thèmes variés. Si l'histoire politique (de l'Europe mais aussi du Proche-Orient) est constamment évoquée, parfois sous un angle inattendu (intérêt de Gagarin pour le révolutionnaire Herzen), elle constitue plutôt une toile de fond et l'apport le plus significatif des documents concerne l'histoire culturelle et religieuse.

5 Les premiers contacts entre bollandistes et jésuites russes au début des années 1850 s'expliquent par une demande d'expertise bruxelloise sur des saints slaves. Cependant, outre les questions spécifiques d'hagiographie et d'histoire religieuse orientales, ces correspondances révèlent de façon concrète le monde de l'érudition européenne au XIX ${ }^{e}$ siècle, façonné par la circulation des livres, les contacts avec les éditeurs et les libraires, les échanges d'ouvrages ou de transcriptions de documents et surtout les innombrables projets de collaborations intellectuelles. De Buck et Gagarin ne sont pourtant pas que des érudits. De Buck apparaît ainsi comme un bollandiste «de terrain ", en quête de matériel sur les jésuites victimes de la Commune de Paris. Surtout, ces hommes veulent développer un mouvement d'opinion pour la réunion de l'Église russe - et, au-delà, de tous les chrétiens séparés - au catholicisme. Ils écrivent parfois sous pseudonyme ou de façon anonyme - des opuscules ou des chroniques dans la presse pour façonner l'opinion. Selon De Buck, pour conjurer le schisme, il faut « faire du bruit » (doc. 19, doc. 83). Cependant, alors que le bollandiste désire un modèle déconcentré d'action par la presse dans différents pays - comme il le fait lui-même dans le Journal de Bruxelles -, Gagarin caresse à plusieurs reprises le projet d'un « journal particulier » (doc. 102).

6 L'ouvrage est aussi particulièrement riche pour l'histoire interne du catholicisme. Fondé sur une vingtaine d'années de correspondance dans le monde jésuite francophone, il apporte de nombreux éléments sur la Compagnie en France, en Italie, 
en Belgique, mais aussi dans les missions lointaines comme l'Inde, et on apprend beaucoup sur « l'apostolat intellectuel » jésuite (notamment sur la revue Études, fondée par Gagarin en 1856). Par ailleurs, les contacts variés des protagonistes (Migne, Moroni, William Palmer, Haxthausen, Dupanloup, Malou, Strossmayer, Duchesne, Falloux, Feliński...) dessinent d'intéressantes articulations au sein de ce catholicisme européen, qui n'ont été pour le moment qu'assez peu abordées par l'historiographie. Ces correspondances offrent ainsi un témoignage de premier plan sur le pontificat de Pie IX, imprégné par un « ultramontanisme » croissant auquel ni De Buck ni Gagarin n'adhèrent, même si cette édition permet de nuancer le "libéralisme » supposé du bollandiste (p. $30 \mathrm{sq}$ ). Le rapport à Rome et à la Curie mérite attention : ces hommes qui sont des experts (Martynov et De Buck sont théologiens au Concile du Vatican et Gagarin a manqué de l'être) font preuve en privé d'un certain anticurialisme (doc. 66), mitigé par la volonté d'avoir un impact auprès des milieux romains, comme le démontre le souci de publier dans La Civiltà Cattolica.

7 L'ouvrage apporte enfin bien sûr beaucoup sur la question de «la réconciliation des Églises». Si l'accent est mis sur l'orthodoxie, notamment russe, les protagonistes évoquent souvent le protestantisme, en particulier l'anglicanisme. La ferme conviction, partagée par ces hommes, est que « $1^{\circ}$ le schisme, (...) est un grand mal dans l'Église ; $2^{\circ}$ c'est donc une obligation pour tous les chrétiens à travailler, selon leurs forces, à faire disparaître ce mal» (doc. 100). Si Martynov s'affirme " pessimiste» (doc. 530), De Buck et Gagarin ne cachent pas leurs espoirs, comme en témoigne le projet fantaisiste de Gagarin d'un concile d'union sur les rives du Bosphore (doc. 217) ou le «rêve » de De Buck d'être envoyé en Russie (doc. 1, 359). Faut-il pour autant considérer cet œcuménisme avant l'heure comme une «naïveté» (p.41)? De Buck récuse le qualificatif de rêveurs pour Gagarin et Haxthausen (doc. 97) et, au fil de la correspondance, la réalité évolue : grâce à la "publicité ", les responsables romains s'intéressent à la question (doc. 188), comme le confirme la création en 1862 de la congrégation de la Propagande pour les affaires du rite oriental. Cependant, quelle est la nature de l'union que ces hommes désirent? Correspond-elle simplement à un " unionisme ", c'est-à-dire - à la différence de l'œcuménisme plus tardif dans le monde catholique et caractéristique de la période Vatican II - à une union ramenant les chrétiens séparés à l'unité catholique, si besoin par des conversions individuelles ? La réponse n'est pas si simple. Certes, les moyens envisagés sont bien caractéristiques de l'unionisme : prière, étude parfois associée à la polémique (ici avec Khomiakov, l'abbé Guettée), projet de réunion sur un mode conciliaire "florentin» associé à des concessions d'autonomies rituelles dans une "pureté » maximale. Cependant, Gagarin et De Buck manifestent leur respect pour les autres chrétiens, en soignant leur langage, au moins dans l'expression publique («réunion» plutôt que "conversion»; " orthodoxe » plutôt que «schismatique »). De Buck encourage ainsi Gagarin à ce que ses écrits, comme La Russie sera-t-elle catholique? - sur lequel nous apprenons ici beaucoup -, soient un « éloge de la Russie» (doc. 8). De Buck insiste : il appelle de ses vœux une "théologie irénique avec des termes et de la philosophie patristico-grecs " (doc. 174) car «c'est la paix qui doit vaincre et non pas la logique ni l'érudition » (doc. 32). En ce sens, les débats théologiques doivent être aplanis, quitte à se « contenter (...) du purgatoire du concile de Trente et d'un Pape gallican, même très gallican » (doc. 32), ce qui implique une perspective critique sur le catholicisme. Les propos de De Buck sur les ordinations anglicanes et la communication in sacris attireront d'ailleurs brièvement l'attention du Saint-Office en 1864 (p. 29-30). L'ouvrage de Danieluk et Joassart invite 
donc à de nouvelles études sur cette période complexe de construction de l'unionisme catholique et, au-delà de cet apport essentiel pour les spécialistes des relations interconfessionnelles, il offre une importante contribution à la recherche sur l'histoire religieuse et culturelle de la seconde moitié du XIX ${ }^{e}$ siècle.

\section{AUTEURS}

\section{LAURA PETTINAROLI}

Institut catholique de Paris. 